Article

\title{
Assessing the Influence of Prior on Subsequent Street Robbery Location Choices: A Case Study in ZG City, China
}

\author{
Dongping Long ${ }^{1}{ }^{\mathbb{D}}$, Lin Liu ${ }^{2,3, *} \mathbb{D}^{\mathbb{D}}$, Jiaxin Feng ${ }^{1}$, Suhong Zhou ${ }^{1}$ and Fengrui Jing ${ }^{1}$ \\ 1 Center of Integrated Geographic Information Analysis, School of Geography and Planning, \\ Sun Yat-sen University, Guangzhou 510275, China; longdp@mail2.sysu.edu.cn (D.L.); \\ fengjx5@mail2.sysu.edu.cn (J.F.) eeszsh@mail.sysu.edu.cn (S.Z.); jingfr@mail2.sysu.edu.cn (F.J.) \\ 2 School of Geographical Science, Center of GeoInformatics for Public Security, Guangzhou University, \\ Guangzhou 510275, China \\ 3 Department of Geography, University of Cincinnati, Cincinnati, OH 45221-0131, USA \\ * Correspondence: lin.liu@uc.edu; Tel.: +86-20-8011-3332
}

Received: 17 March 2018; Accepted: 30 May 2018; Published: 31 May 2018

\begin{abstract}
The literature shows that offenders' subsequent crime location choices are affected by their prior crime location choices. However, the published studies have focused on the influence of time and place of a previous crime, without testing the impact of whether the offender was arrested during the act of the prior crime. On the basis of the literature, this study further examines the influence of the prior robbery experiences on the subsequent street robbery location choices, by testing explicit hypotheses on how the time, place, and being arrested in the act of previous robberies affect a robber's subsequent decisions of where to commit robberies. The data set used in this study includes 1262 detected robberies committed by 527 street robbers from the ZG City Public Security Bureau in China. Results of a mixed logit model demonstrate that prior street robbery experiences have a strong effect on subsequent street robbery location choices. A shorter time interval and less possibility of being arrested in the act of a prior street robbery significantly increase the likelihood of a robber returning to the previous location. However, the impact of distance of journey to prior crime location is not statistically significant.
\end{abstract}

Keywords: street robbery; location choice; crime experiences; repeat offending; mixed logit model

\section{Introduction}

Understanding how offenders choose a crime location is a classic criminological problem [1]. The previous studies on the crime location choice of street robbers mainly follow two perspectives. One aims to explain the spatial pattern by various influencing factors [2-9]. The other studies are based on a recency perspective to examine the influence of the prior on subsequent crime location choices $[10,11]$, and suggest that offenders are more likely to return to the same area if prior offenses occurred more recently.

Although the phenomenon that both initial and subsequent street robberies were committed by the same offenders had been found in the study of repeated offending [12-14], most studies viewed street robberies as isolated incidents that were irrelevant to the former criminal activities and experiences of the street robbers [15]. Lammers et al. lamented that existing literature ignored the probability that offenders' present crime location choices could be affected by their past crime location choices [10]. Similarly, Bernasco et al. highlighted the problem that none of the studies on burglary location choice had explored how the crime experiences of previous burglaries might affect a burglar's subsequent decisions of where to commit crimes [11]. 
Why do offenders return to prior crime locations? Bernasco et al. argued that the locations of former crimes might be important places in the minds of offenders, which could possibly determine the latter crime location choices [3]. Johnson thought that it would be possible for offenders to assess security measures, high-reward areas, and escape routes in an area they had targeted before, and to make full use of the information in future crimes [16]. Townsley et al. believed that offenders might learn from previous offenses or adjust their benefits to the maximum in accordance with prior experience [17]. In general, these studies put forward the view that offenders' former crime experiences have an influence on their subsequent crime location choices.

In the empirical study of repeated crime, a few researchers have focused on detected crimes and their offenders to analyze the influence of the time and place of the previous offenses on the subsequent crime location choices. The findings of Lammers et al. In the Hague, Netherlands indicated that offenders tended to return to former targeted area, in particular to those of recent and nearby crimes and especially if the former crimes were of the same crime type [10]. Bernasco et al. also found similar results in the study of Midlands County, England, pointing out that burglars were more likely to target an area where they had burglarized before, especially if the preceding burglary was more recently committed and the newly targeted area was nearer to the former one [11].

This paper aims to further explore the issue of repeated crime location choices, with a focus on an offender's prior experience of arrest. It differs in three key respects from the prior research by Lammers et al. and Bernasco et al. First, this article not only studies the influence of time and place of previous crimes, but also examines the effect of whether an offender was arrested in the act of a prior crime. Second, studies have shown that different types of crimes have different spatial patterns and their contributing factors are different; while Lammers et al. studied all types of crime as a whole and Bernasco et al. studied burglary, the present study focuses on street robbery. Finally, the context in China enriches the diversity of study areas in terms of criminology of place, whereas those of Lammers et al. and Bernasco et al. are in western countries (Netherlands and England). It is worth pointing out that empirical crime research based on official police data is rare in China, perhaps because the crime data is very difficult or almost impossible to access. Thus, this empirical study will add a valuable piece to the scarce literature.

\section{Theoretical Foundation, Conceptual Framework and Hypotheses}

To better understand the choices of crime location from the street robbers' standpoint, it is useful to first present a theoretical foundation on crime pattern theory, rational choice theory, and social disorganization theory, followed by a conceptual framework and explicit hypotheses to be tested in this study.

\subsection{Crime Pattern Theory}

Crime pattern theory provides some theoretical explanations for why offenders commit several crimes in the same area [10]. Firstly, an area may have a number of high schools, shopping malls, and transportation hubs [3,18-21]. These places can be considered as "crime generators" [22], which are easily accessible to the public, and may become crime hotspots because the existence of large crowds creates opportunities for street robbers [5].

Secondly, an area also has a large number of daily activity places, such as bars, clubs, cybercafés, grocery stores, hotels, restaurants, ATMs, banks, and other places [3,5,23-25]. These places can be seen as "crime attractors" [22]. Large crowds don't necessarily converge here at the same time, but frequent cash transactions are featured, making it an ideal "hunting ground" for street robbers. For example, Jean found that robbers in Chicago were mainly attracted to small markets dominated by cash transactions [26]. Consequently, these activity nodes are well suited for motivated street robbers to search for attractive or weakly guarded targets.

Lastly, the offender's spatial awareness is limited. For instance, street robbers typically have familiar knowledge of the area in the proximity of their residence and around specific activity nodes [3]. 
They do not stay away from this awareness space because the risk level may increase outside of their awareness space [27]. In addition, some researchers suggested that street robbers' spatial awareness played a key role in the choice of crime location, as it determined how benefits, efforts, and risks were perceived $[2,3,28]$. Therefore, street robbers usually find suitable targets not far from their residence, which not only helps them find high yields more easily, but also helps them flee the scene quickly, thus reducing the risk of being arrested. In short, the potential criminogenic places and the limited spatial awareness of crime pattern theory help explain why street robbers tend to commit crimes in the same area.

\subsection{Rational Choice Theory}

Rational choice theory argues that an offender's decision-making is rational, but it is bounded or limited by the differences in individual characteristics, financial needs, crime opportunities, social factors, and so on [29]. Subsequent studies further suggested that an offender made a decision on whether to commit a crime from the perception of benefit, effort, and risk [30,31]. Morrison and O'Donnell showed that the majority of robbers were able to accurately assess the potential benefits and choose the suitable targets, and pointed out the strategies for reducing the risk of being caught, such as choosing the quietest time of the day to rob [32].

Meanwhile, rational choice theory holds that anyone can commit a crime if he or she encounters risk-free criminal opportunity. For example, a person who typically does not commit crime may offend in the case of high rewards and not being caught [31]. In addition, it differs from the traditional criminology theory that the criminal behavior is unavoidable. When the risk of being arrested is high or the criminal income is small, a person may not commit a crime [30,31].

Finally, it suggests that rational offenders learn from their prior crimes to achieve greater benefit or lower risk in subsequent crimes [33]. For instance, Townley et al. thought that the offenders could learn from previous crimes or adjust their preferences to maximize benefits on the basis of past experiences [17]. Additionally, offenders tend to return to their previous successful areas where they can find rich places [3,5] or get cash quickly [34]. Thus, rational street robbers would be likely to analyze the crime experiences of their former offenses, such as whether they were chased by crowds or rounded up by the police? Whether they were arrested on the spot or could easily escape? How long was the distance of journey to crime (J-T-C)? Through a series of analyses, they determine to whether return to the prior crime area to search for targets and commit crimes.

\subsection{Social Disorganization Theory}

Social disorganization theory focuses on how the neighborhood's social composition may make it resist or promote criminal activity $[35,36]$. Scholars have argued that central to such theories is the concept of social cohesion, which facilitates residents to act with collective efficacy to prevent crime [37-39]. Existing research suggests that social cohesion is more likely to appear in the neighborhoods with a stable population, where the residents can form good social ties [40-42], and the residents of a homogeneous community are more likely to share similar goals and beliefs [39,43].

Theories of social disorganization explain the occurrence mechanism of crime from three aspects. First, the close social ties between neighbors can form collective efficacy to reduce opportunities for crimes [42]. For example, residents may assert informal control over others who live nearby, reducing the likelihood of their involvement in crime [39]. Second, communities with strong socioeconomic heterogeneity are less likely to collectively resist criminal activities, because of the lack of cohesiveness among residents who come from very different socioeconomic backgrounds [37]. For example, Liu et al. found that the urban villages and old towns in ZG City, China, are the main "hunting grounds" for offenders because of the greater mobility and higher socioeconomic heterogeneity of residents in these areas [44]. Third, the perception of social cohesion by offenders may influence where they decide to commit an offense [39]. For instance, Bernasco and Nieuwbeerta consider that social cohesion may act as an impedance factor that deters offenders from targeting a neighborhood [45]. 


\subsection{Conceptual Framework and Hypotheses}

Based on the aforementioned theories and literature, this current study aims to analyze the preference of offenders' crime location choices from the perspective of repeated crimes. Figure 1 presents a conceptual framework for assessing street robbers' choice of crime location. The groups of factors are considered: robbers' individual experiences and community characteristics.

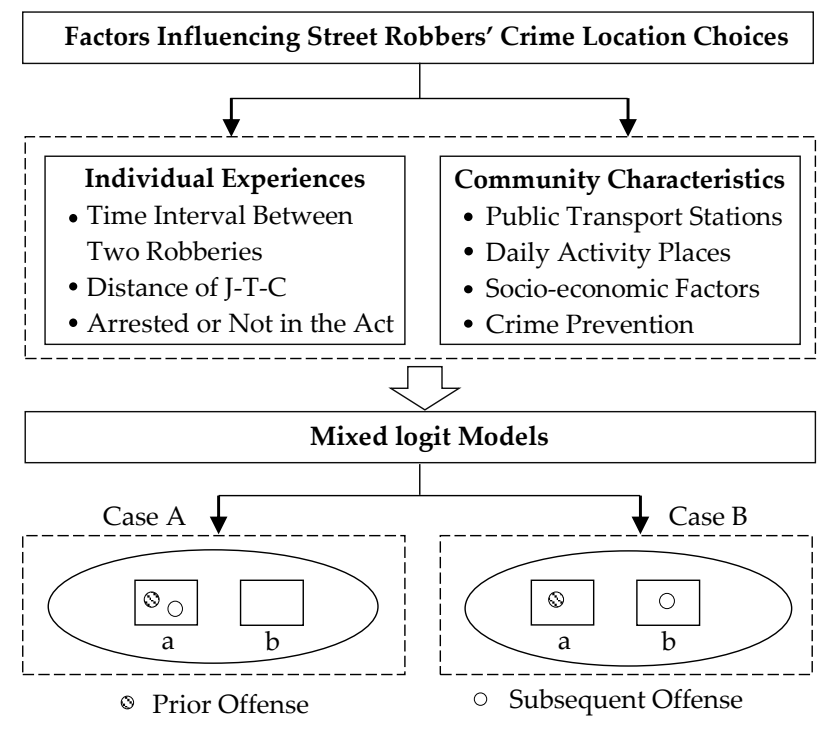

Figure 1. Conceptual Framework on Street Robbers' Choice of Crime Location. Case A means that the locations of prior and subsequent offenses occurred in the same community (community a), and case B means they occurred in different communities (community a and community b).

In this conceptual framework, the robbers' individual experience includes three aspects: (1) time interval between two robberies (the prior and subsequent offenses); (2) distance of journey to prior robbery; and (3) being arrested in the act of a prior robbery (or not arrested in the act). Based on the review of the literature, and the fact that prior robberies represent positive learning experiences to some extent, we suggest that a shorter time interval, shorter distance of journey to crime, and less possibility of being arrested in the act of prior street robbery increase the likelihood of a robber returning to the previous location. Time interval between two robberies (recency) is important because in a short time period the information obtained by the offender is more likely to be accurate and the environment is less likely to change [46,47], and thus their decision criteria remain stable. For example, a recent study suggests that a street robber's location choices hardly vary over time of day or day of week [23]. The distance of journey to prior robbery may play an important role, as a shorter journey may provide more learning experiences for offenders to become familiar with the areas near their residence [10,27]. Being arrested or not in the act of a prior robbery refer to the previous individual experiences at a specific moment, which means being arrested in the act is an immediate negative consequence and not being arrested in the act is a delayed negative consequence. Analogously, the resulting reduction in criminal arrests significantly increases the incidence of crime [48]. Benson found that the probability of arrest represents police production of crime deterrence, which negatively impacts criminal behavior of offenders [49].

It is worth mentioning that the community characteristics in the conceptual framework (discussed in our review of the theoretical foundation literature) also serve as the decision-making criteria for offenders, including indicators of benefits, efforts, and risks of target locations. In this study, they are not explicitly stated as hypotheses but are again tested in the form of control variables, because they are not the main focus of our analysis. 
Generally, in addition to the community related variables, street robbers' choices of subsequent crime location is also affected by their individual experiences, including the time interval between two robberies, distance of journey to prior robbery, and not being arrested in the act of a prior robbery.

These two groups of variables are then fed into a mixed logit model to assess the influence of a robber's prior experience on subsequent street robbery location choices. Meanwhile, the random intercept is incorporated into the model. Specifically, this study tests the following three hypotheses:

Hypothesis 1. Following a previous robbery, a robber is more likely to commit a subsequent robbery in the same area if the time interval between the prior and subsequent offense is shorter.

Time interval is defined as the time elapsed between a prior offense and a subsequent offense. Empirical research has shown that repeated crimes committed in a relatively short period of time against the same or nearby target (or place) usually involve the same offender [14,50,51]. Further, some researches on the offenders also found that if time interval is short (recency), subsequent crimes are likely to occur in an area they have targeted before $[10,11]$. This study tests if the time interval between two robberies of a street robber has an impact on his/her subsequent crime location choices.

Hypothesis 2. Following a previous robbery, a robber is more likely to commit a subsequent robbery in the same area if the distance of journey to previous robbery is shorter.

The distance of journey to crime refers to the distance between an offenders' residence (or other anchor points) and the place they targeted [52,53]. The effect of distance of journey to a prior robbery on the choice of subsequent robbery location is analyzed in this paper. In line with previous studies $[7,54,55]$, this paper measures distance of journey to crime by Euclidean distance. Some studies argued that the residence of an offender is close to or surrounded by his or her crime targets [10,27]. That means there is a significant distance decay effect in the search of potential targets. Whether at the individual or aggregate level, this effect shows that the offender is less likely to offend in an area far away from his or her residence $[7,11,56]$. In other words, the distance of journey to crime is rather short. This study tests whether or not the travel distance of a street robber in previous offenses has an impact on his subsequent crime location choices.

Hypothesis 3. An offender not arrested in the act of a prior robbery is more likely to return to the same area for future robbery, compared with those who were arrested in the act.

Street robbery occurs outdoors, so robbers' concealment is lower and the risk of being arrested in the act is higher. Cornish and Clarke argued that crime location choices of offenders would be affected by the outcomes (e.g., arrest) of their previous crimes [57]. Bernasco et al. considered that the fear of being arrested might not be a decisive factor when offenders decided where to commit crimes, and arrests after prior offenses might not affect their subsequent crime location choices [11]. However, Lammers et al. made a point that offenders might be more likely to return to the area they previously targeted without being arrested [10]. Thus, this paper tests if a street robber not arrested in the act of a former crime is more likely to return to the same area for future robbery.

\section{Data and Methods}

\subsection{Study Area and Data Sets}

ZG City is located at the northern part of the Pearl River Delta, on the southeastern coast of China. It is one of the largest cities in China, with a total permanent resident population of 14.04 million (not including about 2 million unregistered migrant workers) in 2016. The GDP was $¥ 1.96$ trillion (nearly \$ 0.32 trillion) in 2016, with an annual increase rate of $8.35 \%$. The study area covers 1973 communities (Figure 2), with an average size of $1.62 \mathrm{~km}^{2}$. The standard deviation of the size of the 
communities is 2.85 , the minimum size of $0.001 \mathrm{~km}^{2}$ and the maximum size of $43 \mathrm{~km}^{2}$. Figure 2 shows the kernel density (Gaussian kernel function with $1 \mathrm{~km}$ bandwidth) of street robbery with community boundary in the study area.

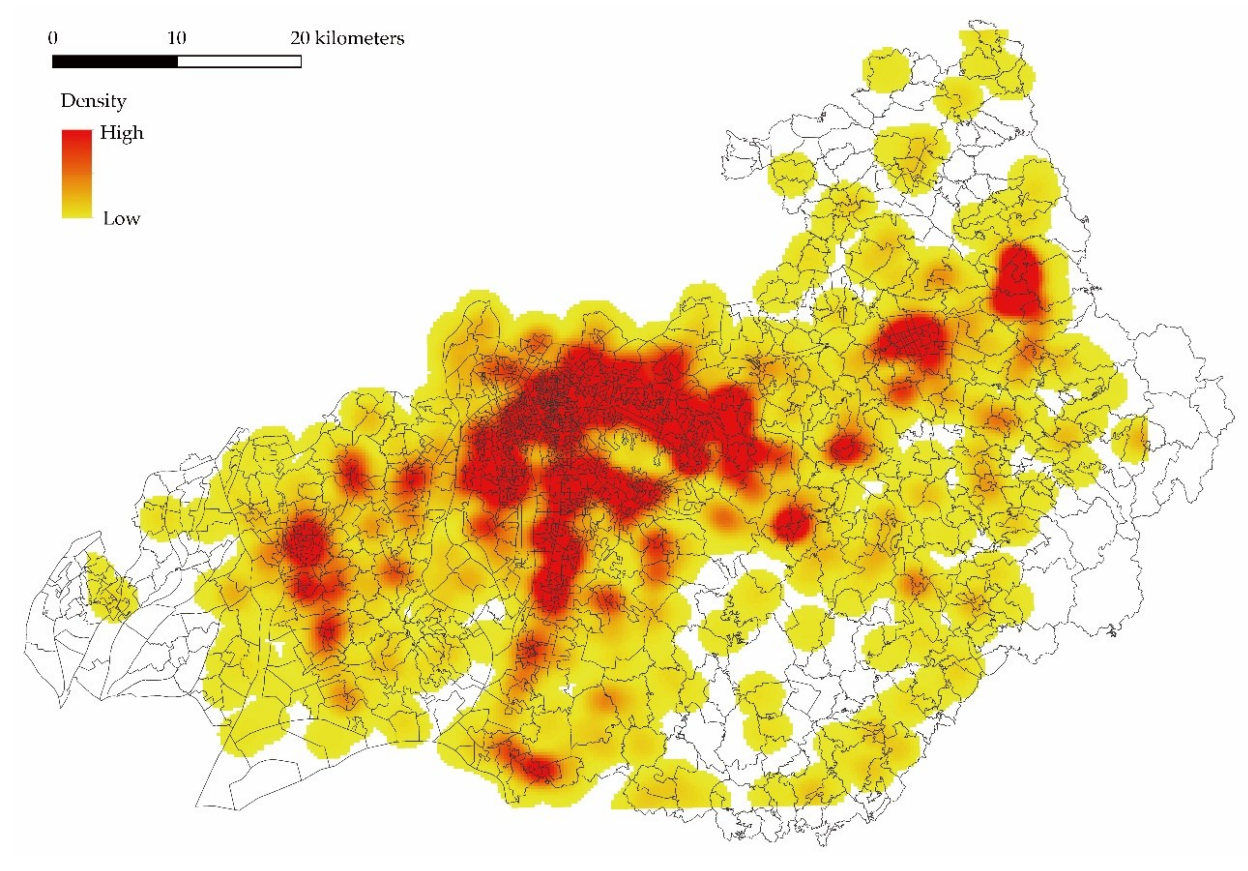

Figure 2. The Kernel Density of Street Robbery in ZG City, China.

\subsubsection{Crime Data and Measurements of Variables}

Crime data on arrested street robbers and their offenses between 2012 and 2016 are provided by the Public Security Bureau of ZG City (see Figure 2). Street robbers use threats or physical force to take property away from their victims [3]. Similar to existing research, the "cleared" street robbery is one that has been reported to the police, and at least one person has been prosecuted. The dataset contains information on offenders of cleared robberies. It includes the time and date of street robberies; the address and spatial coordinates of street robberies (with $1 \mathrm{~m}$ resolution); the residence of street robbers (address and geographic coordinates with $1 \mathrm{~m}$ resolution); and their identity information such as gender, nationality, hukou status (locals vs. immigrants), name, date of birth, and so on; as well as the object, the tool, the place, and the way of committing crime; and the amount of lost property or money. A unique identifier for each robber enables the identification of repeat offenders: by comparing street robbers' names, gender, date of birth, hukou status, and so on.

The data includes 11,455 cleared robberies, among which 67 percent were committed by a single robber without accomplices, 17 percent were committed by two robbers, and 16 percent were committed by three or more robbers. These proportions should be regarded as a lower bound, because usually some robbers may be arrested, while others who were involved in a robbery have not been arrested. After excluding 2285 robberies of the street robbers who live outside the study area and 1338 robberies of the street robbers of unknown residence, 7882 robberies involving 7087 street robbers remained in this study. For offenses committed by groups of offenders, we refer to Bernasco's way of handling a group of co-offenders as a single decision maker $[3,23]$. A member of a group of robbers is randomly selected as a sample variable (4811 robberies were committed by 1463 groups of robbers; the remaining 3071 robberies were committed by single robbers). For example, for the prior and subsequent street robbery committed by robber A, B, and C, this study randomly selects one of the robbers to construct a sample. Although we have not conducted in-depth analysis for the differences in the choices of crime locations between single robbers and co-offending robbers, we found that there is 
little difference in the spatial distributions of their crime locations in the geocoding process. In addition, Bernasco's study showed that the selection criteria of single offender and multiple offenders are the same [58]. Therefore, the above approach was reasonable.

Finally, a total of 527 street robbers involving 1262 street robberies are screened out for further analysis. The characteristics (sex and age) about the sample of street robbers are reported in Table 1. For example, street robbers are almost exclusively men (98.67\%), and there are only 7 females $(1.33 \%)$. At the same time, teenagers and adult robber are the overwhelming majority (96.77\%), and 51 and older robbers are the minority $(3.23 \%)$.

Table 1. The characteristics of street robbers.

\begin{tabular}{lcc}
\hline Variable & Count & Percentage \\
\hline Sex & & \\
Male & 520 & $98.67 \%$ \\
Female & 7 & $1.33 \%$ \\
\hline Age (December 2016) & & \\
12-18 & 58 & $11.01 \%$ \\
$19-23$ & 152 & $28.84 \%$ \\
$24-30$ & 137 & $26.00 \%$ \\
$31-40$ & 109 & $20.68 \%$ \\
$41-50$ & 54 & $10.25 \%$ \\
51 or older & 17 & $3.23 \%$ \\
\hline
\end{tabular}

As Table 2 shows, the count of robberies committed by repeated offenders are as follow: two robberies $(78.18 \%)$, three robberies $(13.09 \%)$, four robberies $(3.98 \%)$, and more than five robberies $(4.75 \%)$. For each repeat robber, pairs of prior and subsequent robberies will be formed. For example, a repeat robber with 2 counts of robberies has 1 pair of prior and subsequent robberies. A repeat robber with 3 counts has 3 pairs, including first-second, second-third and first-third. Likewise, a repeat robber with $n$ counts would have $n(n-1) / 2$ pairs. For repeat robbers, the number of pairs of prior and subsequent street robberies as follow: one pair $(36.85 \%)$, two pairs $(18.52 \%)$, three pairs $(11.27 \%)$, four pairs $(11.63 \%)$, and more than five pairs $(21.74 \%)$. Thus, the total number of pairs of prior-subsequent street robberies is 1118 (see Table 2).

Table 2. Pairs of prior and subsequent street robberies in ZG City, China. (1262 offenses by 527 repeat robbers, 1118 prior and subsequent pairs of street robberies).

\begin{tabular}{ccccccc}
\hline \multirow{2}{*}{$\begin{array}{c}\text { Repeat Robbery } \\
\text { Count }\end{array}$} & \multicolumn{2}{c}{ Number of Repeat Robbers } & \multicolumn{2}{c}{ Number of Robberies } & \multicolumn{2}{c}{ Number of Pairs } \\
\cline { 2 - 6 } & $\mathbf{N}$ & $\mathbf{\%}$ & $\mathbf{N}$ & $\mathbf{\%}$ & $\mathbf{N}$ & $\mathbf{\%}$ \\
\hline 2 & 412 & 78.18 & 824 & 65.29 & 412 & 36.85 \\
3 & 69 & 13.09 & 207 & 16.40 & 207 & 18.52 \\
4 & 21 & 3.98 & 84 & 6.66 & 126 & 11.27 \\
5 & 13 & 2.47 & 65 & 5.15 & 130 & 11.63 \\
6 & 4 & 0.76 & 24 & 1.90 & 60 & 5.37 \\
7 & 7 & 1.33 & 49 & 3.88 & 147 & 13.15 \\
9 & 1 & 0.19 & 9 & 0.71 & 36 & 3.22 \\
Total & 527 & 100 & 1262 & 100 & 1118 & 100 \\
\hline
\end{tabular}

Multiple variables are constructed to test the hypotheses. First, A variable named Repeat Location is created to indicate if the location of a prior robbery is the same as that of a subsequent robbery. If both locations are in the same community, the Repeat Location variable is coded "1" (692 cases, or $62 \%$ of all cases), otherwise " 0 " (426 cases, or $38 \%$ ).

Second, a variable named "Time Interval Between Two Robberies" is measured in days between the prior and subsequent offenses (Table 3). Similar to existing research [10,11], this study consists of 
the following six different temporal categories: (1) 0-2 days, (2) 3-7 days, (3) 8-30 days, (4) 1-6 months, (5) 7-24 months, and (6) $>24$ months. For example, if a repeated offender committed a robbery in a community 5 days prior to the subsequent offense, the temporal category " $3-7$ days" would score " 1 " and others " 0 ". In 0-2 days, 172 subsequent robberies occurred in the same community where the prior robbery occurred, and 38 occurred in different communities. Similar to the above, 3-7 days were 98 and 25, 8-30 days were 171 and 63, 1-6 months were 124 and 81, 7-24 months were 90 and 151, and $>24$ months were 37 and 68 .

Table 3. The time interval of prior and subsequent street robberies $(\mathrm{N}=1118)$.

\begin{tabular}{ccc}
\hline Prior and Subsequent Pairs & $\mathbf{N}$ & $\mathbf{\%}$ \\
\hline Time Interval & & \\
0-2 days & 210 & 18.78 \\
3-7 days & 123 & 11.00 \\
8-30 days & 234 & 20.93 \\
1-6 months & 205 & 18.34 \\
7-24 months & 241 & 21.56 \\
>24 months & 105 & 9.39 \\
\hline
\end{tabular}

Third, a variable named "Distance of Journey to Prior Robbery" is calculated by Euclid distance between the street robber's residence and prior offense location. The mean distance is $4.20 \mathrm{~km}$. Existing research suggests that the attraction of a location is an exponential function of distance from residence [23]. To linearize it, the model for this study used the value of log of the distance. Last, a variable named "Not Arrested in the Act of Prior Robbery" examines whether previous crime experiences affect the subsequent street robbery location choices. The variable is coded " 1 " ( 872 cases, or $78 \%$ ) if a street robber was not arrested in the act of a prior offense (or in the process of escape), otherwise " 0 " (246 cases, or $22 \%$ ). Its average value is 0.78 . The number of occasions where the robber was not arrested in the act in the same community were 629, and 243 in different communities. Accordingly, the number of occasions where the robber was arrested in the act was 22 in the same community and 224 in different communities.

\subsubsection{Community Data and Control Variables}

Considering the context of Chinese cities, the four categories of community variables in Figure 1 are complicated into the following: (1) transportation hubs; (2) subway stations; (3) bus stations; (4) bars and clubs; (5) Cybercafés; (6) malls and supermarkets; (7) high schools; (8) surveillance cameras; (9) daily human mobility; and (10) socioeconomic heterogeneity. In addition, (11) distance of journey to subsequent robbery (Distance of JCR), it also used as the value of log of the Euclidean distance between the street robber's residence and subsequent crime location. These variables are used as the controls in the models.

Except daily human mobility, socioeconomic heterogeneity, and distance of journey to subsequent robbery, other control variables are constructed on the basis of point of interest (POI) in 2014 in ZG City, obtained from a navigation data company in China. POI data include transportation hubs, subway stations, bus stops, Bars and clubs, cybercafés, malls and supermarkets, high schools, restaurants and surveillance cameras, and so on. All points of data are aggregated to the community level.

\subsection{Mixed Logit Model}

The mixed logit model is a family of discrete choice models that estimate the probability of individuals selecting one outcome from exhaustive, mutually exclusive, and limited set of options [59]. The probability is based on observed characteristics of the choosers, the options, and unobserved factors. The mixed logit model is widely used in microeconomics to analyze discrete choice behavior. In view of the fact that an offenders' crime location choice is similar to the above choice, thus, Townsley 
et al. point that this statistical model is especially suitable for panel data because the estimation takes account of the observations nested within decision makers [17].

This mixed logit model is a more general version of the conditional logit model [17]. Recently, some studies have used this model to analyze the strategies of crime location choice. For example, Townsley et al. examined the crime location choices of residential burglars in Brisbane, Australia [17]. Subsequently, Frith et al. also examined the crime location choices of burglars in High Wycombe, UK [60]. In these cases, researchers discussed how offenders' crime location choices were affected by a series of factors, including but not limited to, criminogenic places, human activity, and distance.

Under the premise of controlling the community attribute of prior offenses, this paper assumes a street robber will choose communities with maximize utility to commit subsequent crime. The utility function is calculated as follows:

$$
U_{i j}=\beta_{i} x_{i j}+\varepsilon_{i j}
$$

where $U_{i j}$ is the expected utility of a robbery in community $j$ for street robber $i, x_{i j}$ are the values of the explanatory variables for community $j$ for street robber $i, \beta_{i}$ is a vector of coefficients to be estimated for street robber $i$, and $\varepsilon_{i j}$ is the random error component of the model.

The utility function can be estimated by a mixed logit model. The probability of street robber $\beta_{i}$ choosing community $j$ can be calculated as follows:

$$
\mathrm{L}_{i j}\left(\beta_{i}\right)=\frac{e^{\beta_{i} x_{i j}}}{\sum_{k} e^{\beta_{i} x_{i k}}}
$$

To obtain the probability of unconditional choice, we integrate $\mathrm{L}_{i j}\left(\beta_{i}\right)$ for all values of $\beta_{i}$ :

$$
\operatorname{Prob}\left(Y_{i}=j\right)=\int L_{i j}\left(\beta_{i}\right) f(\beta \mid \theta) d \beta
$$

where $Y_{i}$ is the choice made by street robber $i, \theta$ is the parameters of distribution function $\beta$, such as the mean, standard deviations, and variances etc. In Equation (3), mixed-logit probabilities are the integrals of a weighted average of the logit probabilities evaluated at values of $\beta_{i}$, and the weights given by the normal density $f(\beta \mid \theta)$.

\section{Findings}

First of all, a multicollinearity test is conducted to select independent variables and control variables. It is found that the maximum correlation coefficient of variables named malls and supermarkets is 0.50 , and its VIF value is 1.79 but far less than 10 . Simultaneously, the mean VIF value of these variables is 1.68 , indicating that there is no significant collinearity among the variables. Therefore, all independent variables and control variables will be selected for mixed logit analysis.

Results of mixed logit models (odds ratios, standard error, z-scores, significance level and 95\% confidence intervals, etc.) are listed in Tables 4-6. Three models, such as Model 1, Model 2, and Model 3 respectively tested the effects of time, place, and not being arrested in the act of prior offending on subsequent street robbery location choice.

In addition, it should be pointed out that considering the overall model fit, the McFadden's LRI for the mixed logit model are always much lower than those for ordinary least squares regression models. Actually, it had been confirmed that if McFadden's LRI are greater than 0.20, models can be considered as an excellent fit to the data [61]. Moreover, the P-value of model indicates a degree of significant improvement in a random intercept model versus a fixed-effect logistic regression model, if $\mathrm{P}$ is closer to 0 , the more significant the improvement is [62].

In Table 4, the odds ratios of variables larger than 1 indicate positive effects, and the larger the odds ratios are, the greater the positive effects. On the contrary, the odds ratios of variables smaller than 1 indicate negative effects, and the smaller the odds ratios are, the greater the negative effects. For example, in the first model, the odds ratio of transportation hubs equals 1.42, which means the 
number of transportation hubs in a former targeted community increases by 1 unit, and the odds that a robber targets the same community increase by 42 percent.

This paper first discusses the effects of time of prior offending. The results of Model 1 support Hypothesis 1; its McFadden's LRI is 0.26 and P is 0.000 indicating the first model has a better explanatory ability and has significantly improves. The odds ratios of various "Time Intervals Between Two Robberies" are all greater than 1, and except for the p value of "7-24 months", are larger than 0.05 , other $P$ values of various "Time Intervals Between Two Robberies" are less than 0.01 ( $0-2$ days and $3-7$ days, $p<0.001 ; 8-30$ days and $1-6$ months, $p<0.01)$. This means the influence of "Time Intervals between Two Robberies" is positive and highly statistically significant in four former temporal categories. For a street robber, if occurrence time between former and subsequent offense is closer, then a subsequent crime is more likely to be committed in a prior crime spot. From the effects of "Time Intervals Between Two Robberies" variable, it can be found that street robbers are more likely to repeat in the same area they have previously targeted. Further, as "Time Intervals Between Two Robberies" increases, the value of OR decreases sharply. In comparison with communities which have not been targeted in the past two years, the odds of retargeted communities inflate by a factor 18.10 if offenders have robbed there in the past 2 days. Moreover, the odds inflate by a factor 12.79 if the former robbery was 3-7 days ago, by a factor of 6.05 if it was 8-30 days ago, and by 6.02 if it was 1-6 months ago. For a street robbery occurring 7-24 months ago, although not statistically significant, the odds are still 1.41 times larger. Therefore, the likelihood of street robbers choosing previously targeted areas in a subsequent crime decreases with time.

Table 4. Testing Hypothesis 1 on effects prior on subsequent street robbery location choice from a mixed logit model (Model 1).

\begin{tabular}{lccccc}
\hline Variable & Odds Ratio & Std. Err. & Z & [95\% Conf. & Interval] \\
\hline 0-2 days & $18.10^{* * *}$ & 11.57 & 4.53 & 5.17 & 63.37 \\
3-7 days & $12.79^{* * *}$ & 8.51 & 3.83 & 3.47 & 47.14 \\
8-30 days & $6.05^{* *}$ & 3.77 & 2.89 & 1.78 & 20.54 \\
1-6 months & $6.02^{* * *}$ & 3.85 & 2.80 & 1.71 & 21.11 \\
7-24 months & 1.41 & 0.90 & 0.54 & 0.40 & 4.93 \\
> 24months (ref.) & 1 & 1 & 1 & 1 & 1 \\
Transportation Hubs & $1.42^{* *}$ & 0.19 & 2.67 & 1.10 & 1.84 \\
Subway Stations & $0.84^{*}$ & 0.06 & -2.46 & 0.73 & 0.96 \\
Bus Stops & $1.08^{* * *}$ & 0.02 & 3.78 & 1.04 & 1.13 \\
Bars and Clubs & $1.92^{* * *}$ & 0.35 & 3.56 & 1.34 & 2.74 \\
Cybercafés & $0.67^{* *}$ & 0.08 & -3.36 & 0.53 & 0.85 \\
Malls and Supermarkets & 1.05 & 0.04 & 1.40 & 0.98 & 1.12 \\
High Schools & $1.22^{*}$ & 0.12 & 2.02 & 1.01 & 1.48 \\
Surveillance Cameras & 0.98 & 0.01 & -1.96 & 0.96 & 1.00 \\
Daily Human Mobility $\left(10,000 / \mathrm{km}^{2}\right)$ & 0.78 & 0.12 & -1.67 & 0.59 & 1.04 \\
Socioeconomic Heterogeneity $(10 \%)$ & $0.73^{*}$ & 0.10 & -2.37 & 0.57 & 0.95 \\
Distance of JSR (km) & $0.18^{* * *}$ & 0.05 & -6.77 & 0.11 & 0.30 \\
_cons & 0.16 & 0.18 & -1.62 & 0.02 & 1.47 \\
\hline Random-effects Parameters & Estimate & Std. Err & & {$[95 \%$ Conf. } & Interval] \\
\hline SD(_cons) & 1.54 & 0.28 & & 1.07 & 2.21
\end{tabular}

Note: ${ }^{*} p<0.05,{ }^{* *} p<0.01,{ }^{* * *} p<0.001 ; \mathrm{SD}=$ standard deviation; LR test vs. logistic regression: $P=0.000$; McFadden's LRI $=0.26$.

Model 2 doesn't verify Hypothesis 2 that the influence of "Distance of Journey to Prior Robbery" on subsequent crime location choice (Table 5). Although the McFadden's LRI of Model 2 is 0.19 and its $P$ is 0.000 , the p-value of variable "Distance of Journey to Prior Robbery" is greater than 0.05, which means the influence of "Distance of Journey to Prior Robbery" is not statistically significant. Consequently, Hypothesis 2 is not supported. That is to say, the travel distance of a street robber in previous offenses does not affect his/her subsequent crime location choices. However, in terms of distance control variable, the effect of the distance of journey of subsequent robbery is negative and highly statistically significant $(\mathrm{p}<0.001)$, with an estimated odds ratio of 0.13 . In short, a community 
may become targeted again because the distance between the street robber's residence and subsequent robbery location is relatively shorter.

Table 5. Testing Hypothesis 2 on effects prior on subsequent street robbery location choice from a mixed logit model (Model 2).

\begin{tabular}{|c|c|c|c|c|c|}
\hline Variable & Odds Ratio & Std. Err. & $\mathrm{Z}$ & [95\% Conf. & Interval] \\
\hline Distance of Journey to Prior Robbery & 0.82 & 0.19 & -0.88 & 0.52 & 1.28 \\
\hline Transportation Hubs & $1.31 *$ & 0.18 & 2.02 & 1.01 & 1.71 \\
\hline Subway Stations & $0.85 *$ & 0.06 & -2.22 & 0.74 & 0.98 \\
\hline Bus Stops & $1.08^{* * *}$ & 0.02 & 3.52 & 1.03 & 1.13 \\
\hline Bars and Clubs & $1.90 * *$ & 0.35 & 3.46 & 1.32 & 2.74 \\
\hline Cybercafés & $0.66^{* * *}$ & 0.08 & -3.50 & 0.52 & 0.83 \\
\hline Malls and Supermarkets & 1.05 & 0.04 & 1.28 & 0.98 & 1.12 \\
\hline High Schools & 1.15 & 0.11 & 1.39 & 0.94 & 1.40 \\
\hline Surveillance Cameras & 0.98 & 0.01 & -1.84 & 0.96 & 1.00 \\
\hline Daily Human Mobility $\left(10,000 / \mathrm{km}^{2}\right)$ & 0.79 & 0.11 & -1.64 & 0.59 & 1.05 \\
\hline Socioeconomic Heterogeneity $(10 \%)$ & 0.74 * & 0.10 & -2.31 & 0.57 & 0.95 \\
\hline Distance of JSR (km) & $0.17^{* * *}$ & 0.05 & -6.12 & 0.10 & 0.30 \\
\hline _cons & 0.88 & 0.87 & -0.13 & 0.13 & 6.05 \\
\hline Random-effects Parameters & Estimate & Std. Err. & & [95\% Conf. & Interval] \\
\hline $\mathrm{SD}$ (_cons) & 1.77 & 0.33 & & 1.23 & 2.55 \\
\hline
\end{tabular}

Note: ${ }^{*} p<0.05,{ }^{* *} p<0.01,{ }^{* * *} p<0.001 ; \mathrm{SD}=$ standard deviation; LR test vs. logistic regression: $P=0.000$; McFadden's LRI $=0.19$.

In line with Hypothesis 3, the third model in Table 6 shows the results for the test of whether not being arrested in the act in a previously targeted area influences street robbers' subsequent crime location choice. The McFadden's LRI is 0.23 and P is 0.000 , which indicates that a considerable part of the change of subsequent crime location choice is explicated by the variables contained and significantly improves in this model. Meanwhile, the effect of the variable "Not Being Arrested in the Act of Prior Robbery" is highly statistically significant, with an estimated odds ratio of 8.35. For the same street robber, this result indicates that the probability of returning to a previously targeted area without being caught in the act is very large. That is to say, there may be such a situation that being caught in the act is an immediate negative consequence, and not being caught in the act is a delayed negative consequence. Therefore, this finding supports the third hypothesis. Street robbers are more likely to return to the same area for robbery if they were not arrested in the act before.

Table 6. Testing Hypothesis 3 on effects prior on subsequent street robbery location choice from a mixed logit model (Model 3).

\begin{tabular}{lccccc}
\hline Variable & Odds Ratio & Std. Err. & Z & [95\% Conf. & Interval] \\
\hline Not Arrested in the Act of Prior & $8.35^{* * *}$ & 3.64 & 4.86 & 3.55 & 19.64 \\
Robbery & $1.50^{* *}$ & 0.22 & 2.73 & 1.12 & 2.01 \\
Transportation Hubs & $0.84^{*}$ & 0.07 & -2.25 & 0.72 & 0.98 \\
Subway Stations & $1.09^{* * *}$ & 0.02 & 3.64 & 1.04 & 1.14 \\
Bus Stops & $2.05^{* * *}$ & 0.39 & 3.78 & 1.41 & 2.97 \\
Bars and Clubs & $0.65^{* *}$ & 0.08 & -3.40 & 0.51 & 0.84 \\
Cybercafés & 1.06 & 0.04 & 1.55 & 0.99 & 1.14 \\
Malls and Supermarkets & 1.18 & 0.12 & 1.63 & 0.97 & 1.44 \\
High Schools & 0.98 & 0.01 & -1.60 & 0.96 & 1.00 \\
Surveillance Cameras & 0.80 & 0.12 & -1.52 & 0.60 & 1.07 \\
Daily Human Mobility (10,000/km $\left.{ }^{2}\right)$ & $0.72^{*}$ & 0.10 & -2.45 & 0.56 & 0.94 \\
Socioeconomic Heterogeneity $(10 \%)$ & $0.13^{* * *}$ & 0.04 & -6.92 & 0.07 & 0.23 \\
Distance of JSR (km) & 0.16 & 0.17 & -1.70 & 0.02 & 1.32 \\
_cons & Estimates & Std. Err. & & {$[95 \%$ Conf. } & Interval] \\
\hline Random-effects Parameters & 1.76 & 0.34 & & 1.21 & 2.55 \\
\hline \multicolumn{1}{c}{ SD(_cons) } & & & & \\
\hline
\end{tabular}

Note: ${ }^{*} p<0.05,{ }^{* *} p<0.01,{ }^{* * *} p<0.001 ; \mathrm{SD}=$ standard deviation; LR test vs. logistic regression: $P=0.000$; McFadden's LRI $=0.23$. 


\section{Discussion and Conclusions}

This research is strongly rooted in the large body of literature on geography of crime, especially on spatio-temporal patterns including the near-repeat phenomenon. Most of the previous research focused on patterns, with little regards to the processes. The emphasis on offender's behavior of this study provides insight on the possible mechanisms behind the observed spatio-temporal patterns.

Based on the aforementioned findings, we can conclude that street robbers are more likely to offend in an area they had targeted before if the occurrence time of prior and subsequent crime is closer and the offender was not arrested in the act of prior street robbery.

A shorter time interval between the initial and subsequent offense increases the likelihood of subsequent crimes returning to the area offenders have targeted before. This shows that the likelihood of a prior crime area being chosen by street robbers as a subsequent crime area decreases over time. According to crime pattern theory and ration choice theory, as time and environment changes, the offenders' familiarity with previous crime spots may gradually reduce. Therefore, it confirms that occurrence time of prior street robbery affects offenders' subsequent crime location choices, which is consistent with other published research.

Our finding is consistent with those of Lammers et al. In that offenders are more likely to return to the area they previously targeted without being arrested [10], and Cornish and Clarke demonstrate that street robbers' future crime location choices will be affected by the outcome of the previous crime [57]. However, this finding is different from the view of Bernasco et al. that the location of burglars' subsequent offence isn't affected by their prior arrests. The reasonableness of the standpoint mentioned above includes but is not limited to the following two points. (1) Chinese and Western countries are different in social structure and spatial form, and the role of police and informal social control is also distinct [63-65]. Meanwhile, the spatial pattern and crime place of two types of crime are different $[53,66,67]$. Thus, these differences may account for different decision-making preferences between two types of offenders, as well as the impact of their previous arrests on their subsequent crime location choices; (2) two types of offenders have different cognitions of the result of arrest. Burglars are less worried about being arrested, because they think that the detection rate of burglary is low [68] and solved burglaries are not all handled straightaway [11]. Bernasco et al. pointed out that "arrests after prior burglaries are possibly viewed as misfortunes rather than as mistakes, and may for that reason not affect subsequent target choices ... there is little reason to expect police investigative work would have an impact on burglars' subsequent crime location choices" [11]. However, a rational street robber would view the arrest in the act of prior robbery more as a failure, learn from it and get a fear of being arrested again in the same area. Generally speaking, "being arrested in the act" is more psychological striking than "being arrested by investigation" for an offender. In other words, in a highly stressful situation, street robbers who are suddenly chased and captured would have a strong sense of failure or frustration. Therefore, considering that the population of ZG City is enormous (the total of permanent resident population in 2016 was 14.04 million, excluding about 2 million unregistered migrant workers), and the target of victimization may be seen everywhere, street robbers would choose alternatives in subsequent offense to avoid the selection of their past failure areas.

Why is it less likely for a street robber to reoffend in an area where they have been arrested in the act before? According to the characteristics of the street robbery and the Chinese context, the three main reasons are listed as follows. First, offenders are fearful of being arrested in the act in a prior robbery spot. Street robbers may also be avenged by victims and their relatives or friends. The shadow of "once bitten, twice shy" may linger for a long time. Second, police often use the "patting shoulder," "door-to-door ward rounds," and "greeting and summoning" approaches to remind prior offenders that they are under constant watch. Such interventions, coupled with the facial recognition capabilities of surveillance cameras, inevitably force offenders to commit subsequent crimes far away from the past site. Third, the high level of social cohesion in the Chinese society exerts an influence on repeat offenders. Social cohesion is conducive to the formation of collective efficiency among residents to prevent crime [40,42]. 
However, it seems counter-intuitive that the distance a robber's home to a prior crime location does not play a statistically significant role in affecting a robber's decision to return to offend at a prior offending location. Perhaps this can be explained by the addition of the control variable on the distance from the robber's home location to the subsequent robbery location. The correlation between the two distances is 0.518 . The distance to the subsequent crime location is significant in the model. The interplay between these two distances should be further examined.

It is important to discuss some of the limitations of current research. First, the potential problem of offenses being nested within offenders is not explicitly addressed in this paper. Whether the use of a mixed logit model helps to alleviate this problem needs further examination. Second, the study relies solely on robbery data of the arrested robbers, the omission of un-arrested robbers may bring bias to the model. These issues will be addressed in future research.

In sum, this study provides empirical evidence and suggests that street robbers being arrested in the act of previous robbery has a significant negative impact on their subsequent crime location choices. While there is no reason to believe these findings cannot be applied to other Chinese cities, further research is needed for full validation.

Author Contributions: D.L., L.L. and S.Z. conceived and designed the experiments; D.L., J.X. and F.J. performed the experiments; D.L., J.X. and F.J. analyzed the data; D.L, L.L. and S.Z. contributed reagents/materials/analysis tools; D.L., L.L. and J.F. wrote the paper.

Funding: This research was supported under the National Key R\&D Program of China (Nos. 2018YFB0505500, 2018YFB0505503), Key Program of National Natural Science Foundation of China (No. 41531178), Key Project of Science and Technology Program of Guangzhou City, China (No. 201804020016), Research Team Program of Natural Science Foundation of Guangdong Province, China (No. 2014A030312010), National Science Fund for Excellent Young Scholars (No. 41522104) and Science and Technology Program of Guangdong Province, China (No. 2015A020217003).

Conflicts of Interest: The authors declare no conflict of interest.

\section{References}

1. Townsley, M.; Birks, D.; Bernasco, W.; Ruiter, S.; Johnson, S.D.; White, G.; Baum, S. Burglar target selection: A cross-national comparison. J. Res. Crime Delinq. 2015, 52, 3-31. [CrossRef] [PubMed]

2. Bernasco, W. A sentimental journey to crime: Effects of residential history on crime location choice. Criminology 2010, 48, 389-416. [CrossRef]

3. Bernasco, W.; Block, R.; Ruiter, S. Go where the money is: Modeling street robbers' location choices. J. Econ. Geogr. 2013, 13, 119-143. [CrossRef]

4. Bernasco, W.; Block, R. Where offenders choose to attack: A discrete choice model of robberies in Chicago. Criminology 2009, 47, 93-130. [CrossRef]

5. Bernasco, W.; Block, R. Robberies in chicago: A Block-Level analysis of the influence of crime generators, crime attractors, and offender anchor points. J. Res. Crime Delinq. 2011, 48, 33-57. [CrossRef]

6. Deakin, J.; Smithson, H.; Spencer, J.; Medina-Ariza, J. Taxing on the streets: Understanding the methods and process of street robbery. Crime Prev. Community Saf. 2007, 9, 52-67. [CrossRef]

7. Wiles, P.; Costello, A. The "Road to Nowhere": The Evidence for Travelling; Home Office: London, UK, 2000; ISBN 1-84082-529-4.

8. Xu, C.; Liu, L.; Zhou, S.H.; Ye, X.Y. The spatio-temporal patterns of street robbery in DP peninsula. Acta Geogr. Sin. 2013, 68, 1714-1723.

9. Tang, Y.; Zhu, X.; Guo, W.; Ye, X.; Hu, T.; Fan, Y.; Zhang, F. Non-Homogeneous diffusion of residential crime in urban china. Sustainability 2017, 9, 934. [CrossRef]

10. Lammers, M.; Menting, B.; Ruiter, S.; Bernasco, W. Biting once, twice: The influence of prior on subsequent crime location choice. Criminology 2015, 53, 309-329. [CrossRef]

11. Bernasco, W.; Johnson, S.D.; Ruiter, S. Learning where to offend: Effects of past on future burglary locations. Appl. Geogr. 2015, 60, 120-129. [CrossRef]

12. Farrell, G.; Philips, C.; Pease, K. Like taking candy: Why does repeat victimization occur? Br. J. Criminol. 1995, 35, 384-399. [CrossRef] 
13. Farrell, G.; Pease, K. Once Bitten, Twice Bitten: Repeat Victimisation and Its Implications for Crime Prevention; Home Office: London, UK, 1993; ISBN 1-84082-529-4.

14. Everson, S. Repeat victimisation and prolific offending: Chance or choice? Int. J. Police Sci. Manag. 2003, 5, 180-194. [CrossRef]

15. Long, D.; Liu, L.; Zhou, S.; Du, F.; Song, G.; Xiao, L. Research progress in of criminal behavior from the perspective of geography. Prog. Geogr. 2017, 36, 886-902.

16. Johnson, D. The space/time behaviour of dwelling burglars: Finding near repeat patterns in serial offender data. Appl. Geogr. 2013, 41, 139-146. [CrossRef]

17. Townsley, M.; Birks, D.; Ruiter, S.; Bernasco, W.; White, G. Target selection models with preference variation between offenders. J. Quant. Criminol. 2016, 32, 283-304. [CrossRef]

18. Block, R.; Block, C.R. The Bronx and Chicago: Street robbery in the environs of rapid transit stations. In Analyzing Crime Patterns: Frontiers of Practice; Goldsmith, V., McGuire, P.G., Mollenkopf, J.B., Ross, T.A., Eds.; Sage Publications: Thousand Oaks, CA, USA, 1999; pp. 137-152, ISBN 0-76191-940-6.

19. Chen, J.; Liu, L.; Zhou, S.; Xiao, L.; Song, G.; Ren, F. Modeling spatial effect in residential burglary: A case study from ZG city, china. ISPRS Int. J. Geo-Inf. 2017, 6, 1-13. [CrossRef]

20. Groff, E.R.; Ratcliffe, J.H.; Haberman, C.P.; Sorg, E.T.; Joyce, N.M.; Taylor, R.B. Does what police do at hot spots matter? The Philadelphia policing tactics experiment. Criminology 2015, 53, 23-53. [CrossRef]

21. Kooi, B.R. Assessing the correlation between bus stop densities and residential crime typologies. Crime Prev. Community Saf. 2013, 15, 81-105. [CrossRef]

22. Brantingham, P.L.; Brantingham, P.J. Criminality of place: Crime generators and crime attractors. Eur. J. Crim. Policy Res. 1995, 3, 5-26. [CrossRef]

23. Bernasco, W.; Ruiter, S.; Block, R. Do street robbery location choices vary over time of day or day of week? A test in Chicago. J. Res. Crime Delinq. 2017, 54, 244-275. [CrossRef] [PubMed]

24. Haberman, C.P.; Ratcliffe, J.H. Testing for temporally differentiated relationships among potentially criminogenic places and census block street robbery counts. Criminology 2015, 53, 457-483. [CrossRef]

25. Kurland, J.; Johnson, S.D.; Tilley, N. Offenses around Stadiums: A Natural Experiment on Crime Attraction and Generation. J. Res. Crime Delinq. 2014, 51, 5-28. [CrossRef]

26. Jean, P.K.B.S. Pockets of Crime: Broken Windows, Collective Efficacy, and the Criminal Point of View; The University of Chicago Press: Chicago, IL, USA, 2008; ISBN 0-22677-498-8.

27. Gialopsos, B.M.; Carter, J.W. Offender searches and crime events. J. Contemp. Crim. Justice 2015, 31, 53-70. [CrossRef]

28. Bernasco, W.; Kooistra, T. Effects of residential history on commercial robbers' crime location choices. Eur. J. Criminol. 2010, 7, 251-265. [CrossRef]

29. Clarke, R.V.; Cornish, D.B. Modeling offenders' decisions: A framework for research and policy. Crime Justice 1985, 6, 147-185. [CrossRef]

30. Clarke, R.V.; Felson, M. Routine Activity and Rational Choice: Advances in Criminological Theory; Transaction Publisher: Piscataway, NJ, USA, 1993; Volume 5, ISBN 0-76580-831-5.

31. Felson, M.; Clarke, R.V. Opportunity makes the thief: Practical theory for crime prevention. Police Res. 1998, 1, 1-36.

32. Morrison, S.; O'Donnell, I. An analysis of the Decision-Making practices of armed robbers. In The Politics and Practice of Situational Crime Prevention; Homel, R., Ed.; Criminal Justice Press: Monsey, NY, USA, 1996; ISBN 1-88179-817-8.

33. Johnson, S.D.; Bowers, K.J. The stability of space-time clusters of burglary. Br. J. Criminol. 2004, 44, 55-65. [CrossRef]

34. Jacobs, B.; Wright, R. Stick-Up, street culture, and offender motivation. Criminology 1999, 37, 149-174. [CrossRef]

35. Bursik, R.J. Social disorganization and theories of crime delinquency: Problems and prospects. Criminology 1988, 26, 519-552. [CrossRef]

36. Shaw, C.R.; McKay, H.D. Juvenile Delinquency and Urban Areas; University of Chicago Press: Chicago, IL, USA, 1942.

37. Hirschfield, A.; Bowers, K.J. The effect of social cohesion on levels of recorded crime in disadvantaged areas. Urban Stud. 1997, 34, 1275-1295. [CrossRef] 
38. Sampson, R.J.; Raudenbush, S.W.; Earls, F.J. Neighborhoods and violent crime: A multilevel study of collective efficacy. Science 1997, 277, 918-924. [CrossRef] [PubMed]

39. Johnson, S.D.; Summers, L. Testing ecological theories of offender spatial decision making using a discrete choice model. Crime Delinq. 2015, 61, 454-480. [CrossRef] [PubMed]

40. Braga, A.A.; Clarke, R.V. Explaining High-Risk concentrations of crime in the city: Social disorganization, crime opportunities, and important next steps. J. Res. Crime Delinq. 2014, 51, 480-498. [CrossRef]

41. Coleman, J.S. Social capital in the creation of human capital. Am. J. Sociol. 1988, 94, 95-121. [CrossRef]

42. Weisburd, D.; Groff, E.R.; Yang, S. Understanding and controlling hot spots of crime: The importance of formal and informal social controls. Prev. Sci. 2014, 15, 31-43. [CrossRef] [PubMed]

43. Galster, G.; Santiago, A. Neighbourhood ethnic composition and outcomes for low-income Latino and African American children. Urban Stud. 2017, 54, 482-500. [CrossRef]

44. Liu, L.; Zhang, C.; Feng, J.; Xiao, L.; He, Z.; Zhou, S. The spatial-temporal distribution and influencing factors of fraud crime in ZG city, China. Acta Geogr. Sin. 2017, 72, 315-328.

45. Bernasco, W.; Nieuwbeerta, P. How do residential burglars select target areas? A new approach to the analysis of criminal location choice. Br. J. Criminol. 2005, 45, 296-315. [CrossRef]

46. Johnson, S.D. Repeat burglary victimisation: A tale of two theories. J. Exp. Criminol. 2008, 4, $215-240$. [CrossRef]

47. Johnson, S.D.; Bernasco, W.; Bowers, K.J.; Elffers, H.; Ratcliffe, J.; Rengert, G.; Townsley, M. Space-time patterns of risk: A cross national assessment of residential burglary victimization. J. Quant. Criminol. 2007, 23, 201-219. [CrossRef]

48. Byeon, J.; Kim, I.; Lee, D. Protest and property crime: Political use of police resources and the deterrence of crime. Public Choice 2018, 175, 181-196. [CrossRef]

49. Benson, B.L. The allocation of police. In Handbook on the Economics of Crime; Benson, B.L., Zimmerman, P.R., Eds.; Edward Elgar: Cheltenham, UK, 2010; pp. 184-217, ISBN 1-84720-954-8.

50. Bernasco, W. Them again? Same-Offender involvement in repeat and near repeat burglaries. Eur. J. Criminol. 2008, 5, 411-431. [CrossRef]

51. Johnson, S.D.; Summers, L.; Pease, K. Offender as forager? A direct test of the boost account of victimization. J. Quant. Criminol. 2009, 25, 181-200. [CrossRef]

52. Smith, W.; Bond, J.W.; Townsley, M. Determining how journeys-to-crime vary: Measuring inter-and intra-offender crime trip distributions. In Putting Crime in Its Place: Units of Analysis in Geographic Criminology; Weisburd, D., Bernasco, W., Bruinsma, G.J.N., Eds.; Springer: New York, NY, USA, 2009; pp. 217-236, ISBN 1-44190-973-7.

53. Ackerman, J.M.; Rossmo, D.K. How far to travel? A multilevel analysis of the Residence-to-Crime distance. J. Quant. Criminol. 2015, 31, 237-262. [CrossRef]

54. Snook, B.; Wright, M.; House, J.C.; Alison, L.J. Searching for a needle in a needle stack: Combining criminal careers and journey-to-crime research for criminal suspect prioritization. Police Pract. Res. 2006, 7, 217-230. [CrossRef]

55. Vandeviver, C.; Van Daele, S.; Vander Beken, T. What makes long crime trips worth undertaking? Balancing costs and benefits in burglars' journey to crime. Br. J. Criminol. 2015, 55, 399-420. [CrossRef]

56. Van Koppen, P.J.; Jansen, R.W.J. The road to robbery: Travel patterns in commercial robberies. Br. J. Criminol. 1998, 38, 230-246. [CrossRef]

57. Cornish, D.B.; Clarke, R.V. The Reasoning Criminal: Rational Choice Perspectives on Offending; Springer: New York, NY, USA, 1986; ISBN 1-41285-275-7.

58. Bernasco, W. Co-offending and the choice of target areas in burglary. J. Investig. Psychol. Offender Profiling 2006, 3, 139-155. [CrossRef]

59. Train, K.E. Discrete Choice Methods with Simulation, 2nd ed.; Cambridge University Press: Cambridge, UK, 2009; ISBN 0-52174-738-4.

60. Frith, M.J.; Johnson, S.D.; Fry, H.M. Role of the street network in burglars' spatial decision-making. Criminology 2017, 55, 344-376. [CrossRef]

61. McFadden, D. Quantitative methods for analysing travel behaviour of individuals: Some recent developments. In Behavioural Travel Modelling; Henser, D.A., Stopher, P.R., Eds.; Croom Helm: London, UK, 1978; pp. 279-318, ISBN 0-85664-819-1. 
62. Hamilton, L.C. Statistics with STATA: Version 12; Cengage Learning: Boston, MA, USA, 2012; ISBN 0-84006-463-9.

63. Liu, L.; Li, J.C.M. Progress and future directions of crime research in china with selected case studies. J. Res. Crime Delinq. 2017, 54, 447-453. [CrossRef]

64. Long, D.; Liu, L.; Feng, J.; Song, G.; He, Z.; Cao, J. Comparisons of the community environment effects on burglary and outdoor-theft: A case study of ZH peninsula in ZG city. Acta Geogr. Sin. 2017, 72, 341-355.

65. Zhang, H.; Zhao, R.; Zhao, J.S.; Ren, L. Social attachment and juvenile attitudes toward the police in China. J. Res. Crime Delinq. 2014, 51, 703-734. [CrossRef]

66. Brantingham, P.J.; Brantingham, P.L. Patterns in Crime; Macmillan: New York, NY, USA, 1984; ISBN 0-02313-520-4.

67. Groff, E.R.; Lockwood, B. Criminogenic Facilities and Crime across Street Segments in Philadelphia: Uncovering Evidence about the Spatial Extent of Facility Influence. J. Res. Crime Delinq. 2014, 51, 277-314. [CrossRef]

68. Bernasco, W.; Ruiter, S. Crime location choice. In Encyclopedia of Criminology and Criminal Justice; Bruinsma, G., Weisburd, D., Eds.; Springer: New York, NY, USA, 2014; pp. 691-699, ISBN 0-47067-028-2.

(C) 2018 by the authors. Licensee MDPI, Basel, Switzerland. This article is an open access article distributed under the terms and conditions of the Creative Commons Attribution (CC BY) license (http:/ / creativecommons.org/licenses/by/4.0/). 